\title{
Acute granulomatous iridocyclitis in a child with tubulointerstitial nephritis and uveitis syndrome
}

\author{
Kenan Barut ${ }^{1}$, Turkay Rzayev ${ }^{1}$, Nur Canpolat ${ }^{2}$, Yasemin Ozluk ${ }^{3}$, Ilknur Tugal-Tutkun $^{4^{*}}$ and Ozgur Kasapcopur ${ }^{1}$
}

\begin{abstract}
Background: Tubulointerstitial nephritis and uveitis [TINU] syndrome is a rare disorder that may also be underdiagnosed. Patients with TINU syndrome typically present with an acute bilateral nongranulomatous anterior uveitis following symptoms of systemic illness.
\end{abstract}

Findings: We report the case of a 15-year-old girl who presented with acute granulomatous iridocyclitis and was diagnosed with TINU syndrome based on renal biopsy findings. Both her uveitis and interstitial nephritis promptly responded to high-dose corticosteroid treatment, and there were no relapses during follow-up of 20 months.

Conclusions: TINU should be included in the differential diagnosis of patients who present with acute granulomatous uveitis.

Keywords: Tubulointerstitial nephritis; TINU syndrome; Uveitis; Granulomatous iridocyclitis

\section{Findings}

\section{Introduction}

Tubulointerstitial nephritis and uveitis [TINU] syndrome is a rare disorder, first described in 1975 [1]. It accounts for less than $2 \%$ of all uveitis cases, but $10 \%$ of cases of acute bilateral anterior uveitis [2]. The diagnosis of TINU syndrome is based on the presence of both acute interstitial nephritis and uveitis in the absence of any other disease that can cause either manifestations [3]. A definitive diagnosis requires the finding of consistent histopathologic changes on renal biopsy specimens [3]. Patients with TINU syndrome typically present with an acute-onset bilateral nongranulomatous anterior uveitis. [3,4] Herein, we report the case of a 15-yearold female who presented with acute granulomatous iridocyclitis associated with constitutional symptoms and who was diagnosed as TINU syndrome based on renal biopsy findings.

\section{Case report}

A 15-year-old female was admitted with a 20-day history of extreme fatigue, loss of appetite, and weight loss $(7 \mathrm{~kg}$ in 1 month). She also had red eyes and decreased vision

\footnotetext{
* Correspondence: itutkun@istanbul.edu.tr

${ }^{4}$ Department of Ophthalmology, Istanbul Faculty of Medicine, Istanbul

University, Capa, 34093 Istanbul, Turkey

Full list of author information is available at the end of the article
}

for 10 days. Her past medical history, as well as family history, were unremarkable. There was no history of any drug use. On physical examination at admission, her weight was $47 \mathrm{~kg}$ (3 to 10 percentile), height was $162 \mathrm{~cm}$ (50 to 75 percentile), and her blood pressure was $110 /$ $70 \mathrm{mmHg}$. Other physical examination findings were normal. Her visual acuity was 0.4 in the right and 1.0 in the left eye. Slit-lamp examination revealed a marked diffuse ciliary injection, mild corneal edema, large granulomatous keratic precipitates distributed in the Arlt's triangle, $4+$ cells in the anterior chamber, Busacca nodules, posterior synechiae, and $0.5+$ cells in the anterior vitreous in the right eye (Figure 1). There were fine keratic precipitates, $3+$ cells in the anterior chamber, mobile pupil, and $0.5+$ cells in the anterior vitreous in the left eye. Anterior chamber flare measured by laser flare photometry was $378 \mathrm{ph} / \mathrm{ms}$ in the right eye and $11 \mathrm{ph} / \mathrm{ms}$ in the left eye. Intraocular pressure was $10 \mathrm{mmHg}$ in the right and $14 \mathrm{mmHg}$ in the left eye. There was no vitreous haze and the fundus was normal in both eyes. Intensive topical corticosteroid therapy was started. Her laboratory findings suggested mild renal insufficiency findings: serum urea was $76 \mathrm{mg} / \mathrm{dl}$, creatinine level was $1.2 \mathrm{mg} / \mathrm{dl}$ (glomerular filtration rate (GFR) $55.8 \mathrm{ml} / \mathrm{min} / 1.73 \mathrm{~m}^{2}$ ) both of which were elevated. The patient's erythrocyte sedimentation rate $[112 \mathrm{~mm} / \mathrm{h}]$ and C-reactive protein (CRP) level $(2 \mathrm{mg} / \mathrm{dl})$ were increased. Complete blood 


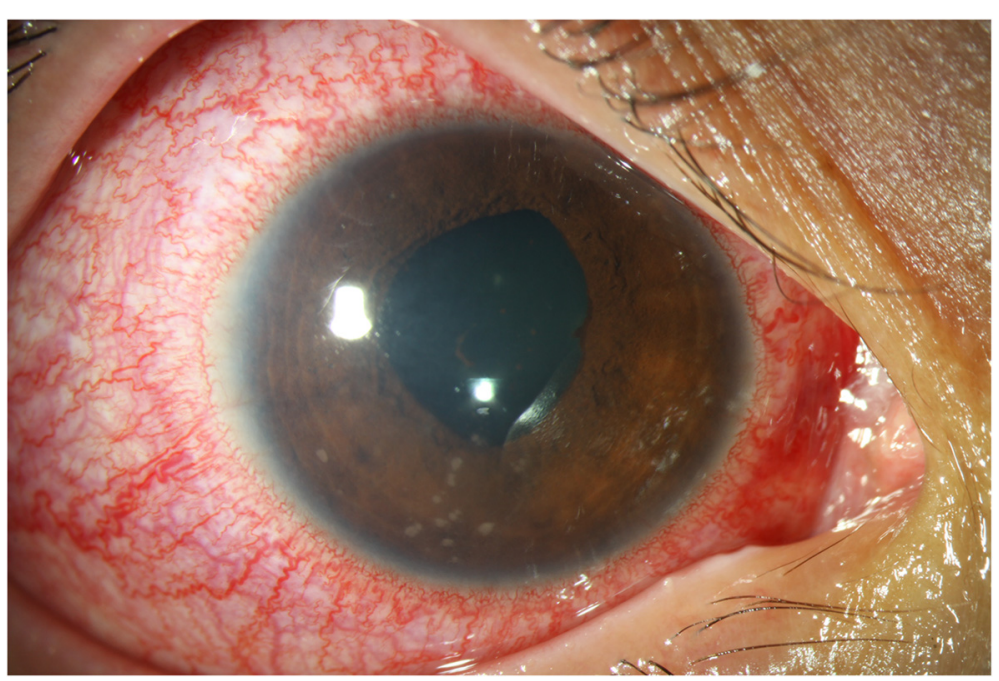

Figure 1 Slit-lamp photograph with TINU syndrome showing ciliary injection, granulomatous keratic precipitates, and an irregular pupil.

count was normal. Antinuclear antibodies were positive in speckled pattern. Anti-ds-DNA $(35.45 \mathrm{U} / \mathrm{ml})$ was elevated (normal value <25). C3 (1.5 gr/l), and C4 $(0.28 \mathrm{gr} / \mathrm{l})$ levels were found to be normal. Urinalysis showed low urine density (1005), normoglycemic glycosuria $(+++$, urine dipstick), and nonnephrotic proteinuria (+, urine dipstick). Spot urine protein level was $112.7 \mathrm{mg} / \mathrm{dl}$; urinary creatinine level was $75.5 \mathrm{mg} / \mathrm{dl}$. We found a high protein to creatinine ratio which was $0.67(n<0.2)$ and high urinary $\beta 2$-microglobulin levels $(45.3 \mathrm{mg} / \mathrm{l}$, normal values 0.02 to $0.25 \mathrm{mg} / \mathrm{l})$. Urinary tract ultrasound examination was normal. Viral serology was noncontributory. QuantiFERON test was done to rule out tuberculosis as a possible cause of granulomatous uveitis, which was found to


Figure 2 Interstitial mixed inflammatory infiltration, tubulitis, and focal granular debris within tubular lumina. Interstitial mixed inflammatory infiltration, tubulitis [small arrows] and focal granular debris within tubular lumina [large arrows]. (A) HE $\times 100$, (B) HE $\times 200 x$. (C) PAS $\times 200$ in the renal biopsy specimen of patient with TINU syndrome. 
be negative. Chest X-ray was normal; angiotensin-converting enzyme (ACE) and lysozyme levels were normal. A renal biopsy was performed. The biopsy specimen showed dense lymphocytes, plasmocytes, and variable eosinophiles in the interstitium and tubulitis in the tubule as well as focal debris and hyaline cylinders in the tubule (Figure 2). Glomerular structures were preserved. There were no vascular lesions. There was no immune complex nephritis. These findings were consistent with acute tubulointerstitial nephritis, and the patient was diagnosed as TINU syndrome. The patient received $2 \mathrm{mg} / \mathrm{kg}$ of prednisone for 3 weeks, and then the dose was tapered and discontinued within 1 month. Her kidney function normalized after prednisone therapy. After about 3 weeks of treatment, sedimentation rate $(24 \mathrm{~mm} / \mathrm{h})$ and CRP level $(0.11 \mathrm{mg} / \mathrm{dl})$ decreased. Urea $(39 \mathrm{mg} / \mathrm{dl})$ and creatinine $(0.9 \mathrm{mg} / \mathrm{dl})$ (GFR $74.3 \mathrm{ml} / \mathrm{min} / 1.73 \mathrm{~m}^{2}$ ) levels returned to normal. Urine analysis, proteinuria, and glycosuria improved rapidly. Uveitis promptly responded to systemic and local corticosteroid treatment, and visual acuity increased to 1.0 within 6 days in the right eye. There were no relapses of uveitis or ocular complications during follow-up of 20 months.

\section{Discussion}

Clinical presentation of TINU is variable. Systemic symptoms such as weight loss, fatigue, arthralgia, and fever may predominate. Renal manifestations include sterile pyuria, hematuria, subnephrotic proteinuria, and renal insufficiency. Ocular symptoms can precede [21\%] or follow [65\%] the renal diagnosis [3]. Our patient had ocular symptoms, weight loss, fatigue, and loss of appetite. Mild renal insufficiency was present. There is no single diagnostic test available for TINU syndrome. Diagnosis is based on the exclusion of systemic diseases such as Wegener's granulomatosis, systemic lupus erythematosus, Sjogren's syndrome, sarcoidosis, rheumatoid arthritis, Behçet disease, tuberculosis, and brucellosis. Our patient's clinical and biochemical features were compatible with renal failure of tubular origin (increased $\beta 2$-microglobulin levels, microalbuminuria, glycosuria, and low urine osmolality), without any sign of significant glomerular involvement (normal serum immunoglobulins and complement and nonnephrotic proteinuria). Renal biopsy confirmed acute tubulointerstitial nephritis with inflammatory tubulointerstitial involvement that spared glomerular structures. Goda and colleagues [5] noted that in 11 of 12 patients with TINU syndrome, urinary $\beta 2$-microglobulin was increased. We also detected increased $\beta 2$-microglobulin levels in our case.

Ocular involvement in TINU syndrome is in the form of nongranulomatous anterior uveitis in $80 \%$ of patients but may also manifest as intermediate, posterior, or panuveitis [3]. Ali and Rosenbaum [6] have recently suggested that sarcoidosis and TINU may have a common pathogenesis based on their observation of inferiorly located chorioretinal scars in four patients with TINU. An anterior uveitis with granulomatous keratic precipitates or iris nodules has been only rarely reported in TINU patients [3]. Our case presented with a severe granulomatous anterior uveitis which may be considered as a more suggestive sign of ocular sarcoidosis. A definitive diagnosis of TINU could be reached by further investigations including renal biopsy.

Our patient responded to the use of high-dose corticosteroid therapy. Her kidney function normalized, and uveitis resolved shortly after induction of treatment. No recurrence of either nephritis or uveitis was observed during tapering or after discontinuation of treatment. However, recurrences and relapses of uveitis have been reported in TINU patients and steroid-sparing immunosuppressive therapy may be required [3].

In conclusion, TINU syndrome is probably an underdiagnosed disorder and should be considered in the differential diagnosis of granulomatous uveitis as well. Diagnostic work-up should include urinalysis and kidney function tests in patients with an acute-onset uveitis with nongranulomatous or granulomatous features. A renal biopsy may be required to make a definitive diagnosis and to exclude confounding entities especially in patients presenting with atypical ocular lesions.

\section{Consent}

Written informed consent was obtained from the patient and her parents for the publication of this report and any accompanying images.

\section{Abbreviations}

TINU: Tubulointerstitial nephritis and uveitis; ph/ms: Photons per millisecond; GFR: Glomerular filtration rate; CRP: C-reactive protein; ACE: Angiotensin-converting enzyme.

\section{Competing interests}

The authors declare that they have no competing interests.

\section{Authors' contributions}

$\mathrm{KB}$ participated in the management of the patient, obtaining clinical data, review of the literature, and drafting of the manuscript. TR and NC participated in the critical management in patient care. YO provided histopathologic evaluation of the patient's kidney biopsy specimen. ITT was involved in the management of the patient's eye disease, brought intellectual content, and revised the manuscript critically. OK was the principal clinician involved in the clinical management of the case, helped to draft the manuscript, and critically revised the final manuscript. All the authors have read and given final approval for the manuscript submitted.

\section{Acknowledgements}

We have not received any support or funding in patient management or in writing of the manuscript.

\section{Author details}

'Department of Pediatric Rheumatology, Cerrahpasa Faculty of Medicine, Istanbul University, Istanbul, Turkey. ${ }^{2}$ Department of Pediatric Nephrology, Cerrahpasa Faculty of Medicine, Istanbul University, Istanbul, Turkey. ${ }^{3}$ Department of Pathology, Istanbul Faculty of Medicine, Istanbul University, Istanbul, Turkey. ${ }^{4}$ Department of Ophthalmology, Istanbul Faculty of Medicine, Istanbul University, Capa, 34093 Istanbul, Turkey. 
Received: 5 January 2015 Accepted: 31 January 2015

Published online: 13 February 2015

\section{References}

1. Dobrin RS, Vernier RL, Fish AL (1975) Acute eosinophilic interstitial nephritis and renal failure with bone marrow-lymph node granulomas and anterior uveitis: a new syndrome. Am J Med 59:325-333

2. Mackensen F, Smith JR, Rosenbaum JT (2007) Enhanced recognition, treatment, and prognosis of tubulointerstitial nephritis and uveitis syndrome. Ophthalmology 114:995-999

3. Mandeville JT, Levinson RD, Holland GN (2001) The tubulointerstitial nephritis and uveitis syndrome. Surv Ophthalmol 46:195-208

4. Mackensen F, Billing $H$ (2009) Tubulointerstitial nephritis and uveitis syndrome. Curr Opin Ophthalmol 20:525-531

5. Goda C, Kotake S, Ichiishi A, Namba K, Kitaichi N, Ohno S (2005) Clinical features in tubulointerstitial nephritis and uveitis [TINU] syndrome. Am J Ophthalmol 140:637-641

6. Ali A, Rosenbaum JT (2014) TINU (tubulointerstitial nephritis uveitis) can be associated with chorioretinal scars. Ocul Immunol Inflamm 22:213-217

\section{Submit your manuscript to a SpringerOpen ${ }^{\circ}$} journal and benefit from:

- Convenient online submission

- Rigorous peer review

- Immediate publication on acceptance

- Open access: articles freely available online

- High visibility within the field

- Retaining the copyright to your article 